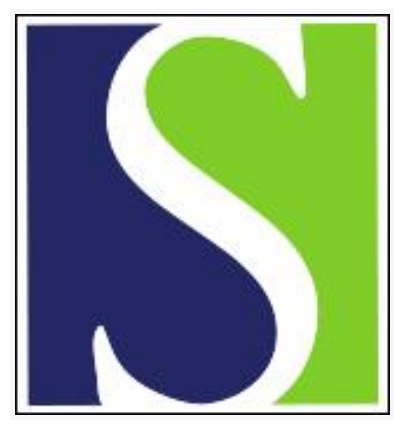

Scand J Work Environ Health 2016;42(4):346-353

https://doi.org/10.5271/sjweh.3567

Published online: 09 May 2016, Issue date: 01 Jul 2016

\title{
Labor markets and health: an integrated life course perspective
}

by Amick BC, McLeod CB, Bültmann U

Integrating a life course perspective into work and health research leads to a new approach to conceptualizing research questions that: (1) account for prior non-work and health states and significant life transitions; (2) offer a new work and health nomenclature reflecting transitions, experiences, trajectories, and context; and, (3) place a primary research focus on labor markets and health trajectories.

Affiliation: Department of Health Policy and Management, Robert Stempel College of Public Health and Social Work, Florida International University, 11200 SW 8 St, AHC 5 - 453, Miami, Florida, 33199 USA. bamickii@fiu.edu

Refers to the following text of the Journal: 2015;41(4):413-416

The following articles refer to this text: 2017;43(1):42-49; 2017;43(4):316-325; 2018;44(6):639-646; 2021;47(7):509-520; 2021;47(7):550-560; 2022;48(5):323-326

Key terms: discussion paper; health; health research; health trajectory; integrated life course perspective; labor market; labor markets and health framework; work

This article in PubMed: www.ncbi.nlm.nih.gov/pubmed/27158797

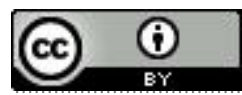




\title{
Labor markets and health: an integrated life course perspective
}

\author{
by Benjamin C Amick, PhD, 1, 2 Christopher B McLeod, PhD, ,2, 3 te Bültmann, PhD, 4
}

\begin{abstract}
Amick BC, McLeod CB, Bültmann U. Labor markets and health: an integrated life course perspective. Scand J Work Environ Health. 2016;42(4):346-353. doi:10.5271/sjweh.3567

Current work and health research is fragmented, focusing on jobs, exposures, specific worker groups, work organization, or employment contracts. An emphasis on the labor market in framing the work and health relationship conceptualizes work not only as an exposure that increases or lessens health risk but also as a life course experience that is dependent on place and time. The intention is to illustrate how the labor markets and health framework coupled with a life course perspective extends other epidemiological approaches to work and health to identify new research questions. Taking the changing nature of work and labor markets into account, this paper updates the labor markets and health framework. It then reviews, defines, and integrates key life course concepts. A model is developed that guides the understanding of how labor markets and health trajectories emerge from the consideration of the working life course in a social context. The application leads to new research questions investigating characteristics of labor markets and health trajectories that may lead to positive health outcomes over the life course.
\end{abstract}

Key terms health research; health trajectory; labor markets and health framework; work.

Maintaining and maximizing a healthy life including a healthy working life, is important for individuals and societies $(1,2)$. To promote health throughout the working life course and extend healthy working lives, a life course perspective must be integrated into work and health research. A life course perspective applied to work and health highlights the importance of prior life experiences, eg, where individuals grew up, who they grew up with, and their education and health status prior to working. Life course transitions, taken together with health transitions (both prior and during working life), health outcomes, labor market experiences, and labor market transitions create an individual's working life course. Current work and health research is fragmented and focuses on jobs, exposures, work organization, or employment contracts (3).

Recently, social epidemiological research on work and family has integrated life course principles into the methodology to examine working life trajectories
$(4,5)$. Social epidemiology has considered theoretical models of exposure broadly focused on the socioecological causes of health $(6,7)$, social triggers of biological events (8), the social structuring of work exposures (9), the role of social context in affecting unemployment (10), and precarious employment contracts (11). While social epidemiological theory has advanced our broad conceptualization, a more integrated approach is needed that considers the working life course (as represented in the example in the box on the following page) from the school-to-workto-retirement transitions and the impact of work on retirement (12).

This paper builds on the earlier labor markets and health framework and seeks to integrate life course principles from the social sciences $(13,14)$. Life course sociology and psychology have a robust theoretical history ranging, for example from Bronfenbrenner's socioecological theory of development (15) to Samp-

1 Department of Health Policy and Management, Robert Stempel College of Public Health and Social Work, Florida International University, Miami, Florida, USA.

2 Institute for Work \& Health, Toronto, Canada.

3 School of Population and Public Health, University of British Columbia, Vancouver, Canada.

4 Department of Health Sciences, Community and Occupational Medicine, University of Groningen, University Medical Center Groningen, Groningen, The Netherlands.

Correspondence to: Benjamin C. Amick III, PhD, Department of Health Policy and Management, Robert Stempel College of Public Health and Social Work, Florida International University, 11200 SW 8 St, AHC 5 - 453, Miami, Florida, 33199 USA. [E-mail: bamickii@fiu.edu] 


\section{An Illustrative Working Life Course}

Our worker experienced depression in adolescence and dropped out of secondary school. When she tried to find work, there were few job opportunities, and the work she found was of low pay, low skill, and often short-term. Eventually, she found permanent full-time employment as a cleaner - a job with harsh physical and chemical exposures and low job control that also required shift work. She found it difficult to continue working full-time as her health started to decline, and she entered a period of work disability. There were few retraining opportunities for her and she struggled to find full-time work. She retired on disability with few material resources.

son's theory of cumulative disadvantage (16) to Mayer's integration of institutional perspectives on life course theories (17). Five key principles emerge from the conceptual life course literature (18): (i) human development and aging are lifelong processes (principle of lifespan development), (ii) individuals construct their own life course through the choices and actions they take within opportunities and constraints of history and social circumstance (principle of agency), (iii) the life course of individuals is embedded and shaped by the historical times and places they experience over their lifetime (principle of time and place), (iv) the developmental antecedents and consequences of the life transitions, events, and behavioral patterns vary according to their occurrence in a person's life (principle of timing) and (v) lives are lived interdependently and sociohistorical influences are expressed through this network of shared relationships (principle of interdependence).

Life course principles have been applied to understand (developmental) health trajectories and socioeconomic inequalities in health (19-23). An important aspect of health relevant to the labor markets and health framework is that health is a determinant and a resource/capability, which shapes the working life trajectories. Adopting the life course perspective in work and health research involves understanding the key principles related to time, duration, intensity and place (context), ie, past and present exposures and experiences that have been or are shaped in a particular social, historical and/or cultural context influence future health and labor market outcomes. In this paper, we seek to integrate these life course principles into a new way of thinking about work and health by: (i) updating the labor markets and health framework accounting for the changing nature of work and of labor markets; (ii) integrating key life course concepts, transitions, critical and sensitive periods, accumulation of risk and chain of risk to understand labor markets and health trajectories (19-21); and (iii) illustrating how the integration of the life course perspective into the labor markets and health framework helps to inform new research.

\section{The labor markets and health framework: an updated view}

Three core dimensions are discussed that build on the original labor markets and health framework: (i) labor market experiences related to the availability of work and the nature of work, (ii) labor market and social contexts, including social actors, and (iii) a life course perspective integrated into the labor markets and health framework.

\section{Labor market experiences: availability of work and nature of work}

The availability of work refers to an individual's connectedness to the labor market (table 1). A worker can be completely disconnected from the labor market (ie, out of the labor force), unemployed (ie, not working but seeking work), underemployed, fully employed and overemployed. While the availability of work describes a series of employment states, there is also a component relating to how work provides the opportunity to use and develop skills and competencies (14).

The nature of work refers to job characteristics or working arrangements (table 1). The nature of work spans physical, chemical, noise, radiation, and psychosocial exposures. It also includes working arrangements such as shift work or multiple job holdings and the type of employment contract and compensation structure. These experiences do not occur in isolation, but are often clustered together such as physically demanding shift work among nurses or repetitive, high-paced work among contract service workers.

Table 1. Labor market experiences: availability and nature of work

Availability of work

- Worker out of the labor market, no longer looking for work

- Unemployed, looking for work, in the labor market (voluntary / involuntary unemployment)

- Underemployed - working less hours than you would like to do

- Fully employed - working for the hours one wants to (includes full-time / part-time work)

- Overemployed - working more hours than you would like to

Nature of work

- Psychosocial resources and demands (eg, control, support, work demands)

- Physical demands (eg, biomechanical, repetitive work)

- Environmental conditions (eg, noise, chemicals, heat)

- Work arrangements / schedule (eg, shift work, multiple jobs)

- Employment contract (eg, temporary, permanent, self-employed)

- Wages, compensation and benefits

a Note: many of these labor market experiences can be bundled together, $\mathrm{eg}$, job strain, which is the combination of job demands and control. 


\section{Labor market and social contexts}

Labor market experiences related to the availability and nature of work are embedded within a labor market and social context (7). Four contextual levels are defined: workplace/organizational, labor market, societal, and supranational (see table 2). At each contextual level, multiple social actors can shape labor market experiences and influence the working life course. The four levels have been only rarely integrated into work and health research.

The working life course example on the previous page illustrates how contextual levels influence labor market experiences over time to create a labor markets and health trajectory. At the workplace/organizational level, effective disability management policies and interventions might have prevented or shortened her work disability episode by providing effective retraining opportunities. Within the labor market, the likelihood and duration of her unemployment is influenced by the availability of job training programs or suitable alternative employment opportunities. After following an effective retraining program she might have found suitable full-time work. Within her societal context, limited access to and availability of unemployment and work disability benefits likely affected her unemployment duration and work disability experiences. A labor market context with better access to work disability benefits might have provided treatment and training opportunities to support her transition back to work. Taken together, her negative labor markets and health trajectory is easily understood. Equally important, her trajectory illustrates opportunities for policy and programmatic actions that could have better supported her and reduced the disadvantages she experienced. Her gender and ethnicity are also important characteristics of the context. These and other individual level factors are often socially structured and addressed in social epidemiological research, but also fundamental to labor markets and health trajectories [(for a more detailed discussion see (14)].

\section{Integrating a life course perspective into the labor markets and health framework}

The intent is to offer an approach that moves research away from a static model of work and health towards a dynamic model of how a person's labor market and health experiences are shaped by labor markets and social contexts into a working life trajectory. This approach builds on and integrates previous occupational, psychosocial, social and life course epidemiological ideas relating to work and health.
Table 2. Core social context levels

Workplace/organizational level

- Organization of work (eg, blended and/or flexible work)

- Organization of work arrangements (eg, availability of flexible work arrangements for child care and informal care)

- Training and career development

- Climate/culture (health and safety and social relations)

- Leadership style

- Labor/Management relations

- Occupational Safety and health and disability management policies and practices

- Health Promotion and Wellness Programs

- Wages and benefits programs

Labor market level

- Local economic conditions

- Resources (physical and human capital - demographics)

- Infrastructure (transportation, zoning and urban planning)

- Industrial mix/composition

- Business (trade) associations

- Education and training programs, including community colleges, certification programs, job training programs, apprenticeship programs

Societal level

- Employment and unemployment policies

- Sick leave and workers compensation

- Labor law

- Collective agreements

- Political system

- Taxation policies

- Health care and pensions; health insurance portability

- Environmental, education, labor policies

- Active labor market policies

- Citizen's rights and privileges

- Transportation

Supranational level

- Trade agreements

- Global economic conditions

- Portability of jobs across borders (EU example of globalization)

Traditional occupational or psychosocial epidemiology research would consider an exposure and how it relates to a health outcome. Typically, exposure is assessed at one point in time (baseline), and then related to a health outcome at follow-up. This is represented by model 1a in figure 1. Often exposures (eg, biomechanical or chemical exposures) are linked to specific work activities or a particular job (with job exposure matrices). When follow-up exposures are assessed (model $1 \mathrm{~b}$, figure 1), dose burden, peak-exposure period or cumulative exposure models can be developed (24). Exposure can be averaged or cumulated over several time points (25). Key challenges are in obtaining follow-up data and consistent exposure measures. But, in all cases there are multiple exposure measures and then the follow-up outcome. 


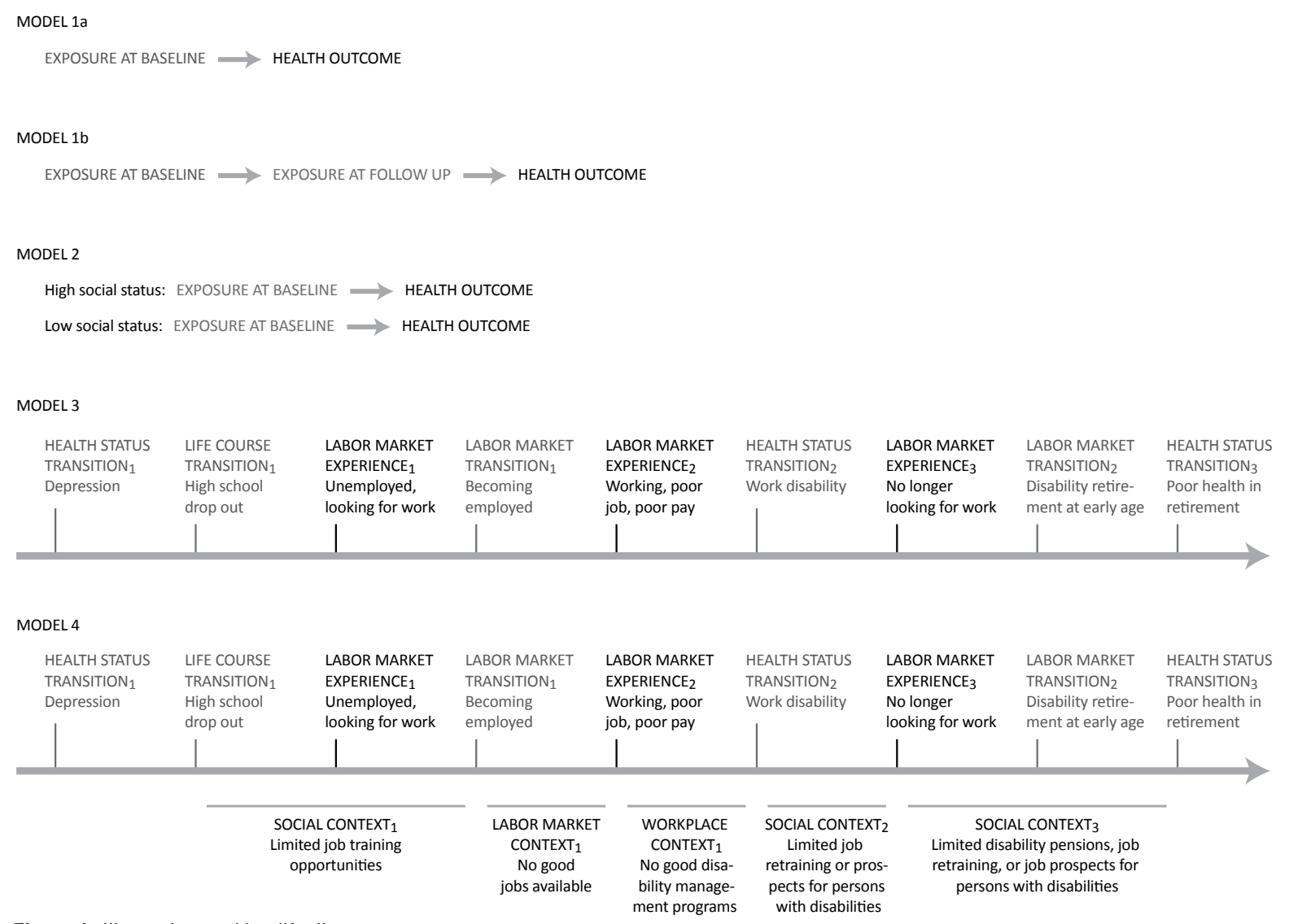

Figure 1. Illustrative working life diagram

Social epidemiological research suggests that the relationship between exposure and outcome is socially structured and not randomly distributed within a society (26). Both models 1a and 1b can be stratified on some social system characteristics (eg, education, income, occupation, socioeconomic position, or immigrant status). Social strata can affect exposure-response models both through selection (ie, determining who is exposed) and through the magnitude of the response to the exposure (see model 2 in figure 1).

Life course epidemiological research suggests that different types of exposures, acting at different time points, affect health later in life. Exposures may: (i) act independently, (ii) be clustered, or (iii) be in a causal chain [see (21) for a more detailed description]. Crucially, and distinct from the previous models, the life course approach permits the consideration of sequencing earlier health and health changes that may influence subsequent exposures and later life health or health changes. Model 3 (based on the working life course example), represents a hypothetical situation with labor market experiences, labor market transitions, health status transitions and health states together. Life course transitions depicted in model 3 represent human development (ie, biological, psychological and social) that occurs throughout the life course.
Transitions are significant changes in physiological, psychological, social or material states $(7,21)$. Transitions (ie, health status, life course and labor market transitions) have the potential for short- and long-term health and labor market outcomes. The working life course is framed by a school-to-work transition at the front-end and a work-to-retirement transition at the back-end (12, 27). These two transitions are not simple. For example, a person can be at school and working while in school. Then leave school and work only to return to school to finish their education. Finally, the person enters full-time employment. Two life course transitions, indicative of other life course events that shape trajectories, often occurring during working life, are marriage and family formation (28). Labor market transitions into and out of the labor market significantly shape the working life course. Model 3 highlights the need to capture the various ways in which individuals engage in the labor market over the working life course creating multiple transitions between different labor market experiences and health states [eg, $(4,29)$ and table 3].

Critical periods and sensitive periods are treated as independent concepts in life course epidemiology. Critical periods are defined as time-limited windows where an exposure can have adverse or protective effects 
Table 3. Overview of labor market and health transitions

Into/out of the labor market
- School to work and/or work to school
- Work into and/or out of retirement
- Work into and/or out of family care
- New labor market entrance (eg, new immigrants)
Within the labor market
- Employment to unemployment and /or out of unemployment to
employment
- Work to maternity/paternity leave and/or maternity/paternity leave
to work
- Connectedness to the labor market, related to the nature of the
contract (working arrangement and time): self-employed to not self-
employed and/or vice versa (vv), part-time to full-time and/or vv)
salary to hourly/piece and/or vv, permanent to temporary and/or vv,
unionized employer to a non-unionized employer and/or vv
- One job to another job
- One firm to another firm
Health-related transitions that affect the work status
- Remain working (accommodated or not)
- Not working, but able to return to work (short-term disability or
sickness absence)
labor market)

on development and subsequent health outcomes. To be defined as a critical period, there must be no excess health risk associated with exposure outside this window $(20,21)$. Sensitive period $(s)$ are defined as a time period when an exposure has a stronger effect on development and subsequent health risk (or advantage) than it would at other times. Outside the sensitive period any excess risk will be weaker (21). Critical periods that influence the working life course typically take place in (early) childhood and adolescence (21). During sensitive periods, exposures may differentially affect individuals' current and future health state, labor market experiences and labor market transitions (30). Sensitive periods are influenced by the context and determined or shaped by the key life course principles. As such, sensitive periods may vary across individuals, time and place. In model 3 , being unemployed and looking for work early in the working life course may be a sensitive period leading to health and labor market outcomes that have both shortand long-term consequences. Other sensitive periods may be becoming employed but working in a poor job with low pay or availability of work for women during childbearing years (31). A sensitive period during the working life course may also be a health state transition. For example, a sickness absence episode due to mental health problems may have a profound effect on future labor market experiences, labor market transitions and long-term health states (32).

Accumulation of risk refers to the accumulation of different types of exposures (eg, environmental, socioeconomic and behavioral) that may cause long- term damage $(21,33)$. Exposure risk can be either independent or clustered, for example, in low social status groups who are at a higher "risk of risks" (21, 33 ). In model 3 , risk accumulation over the working life course would consider whether and how all the different exposures (labor market experiences) and transitions (labor market, life course and health state transitions) accumulate risk for a particular health outcome. Work and health research has considered the independent contributions of exposures and transitions. Although some research has sought to accumulate exposures to define health outcome/disease risk $(10,34)$, research on cumulative labor market and health advantage over the working life course is sparse (14).

Chain of risk refers to a sequence of linked exposures that raise health risk (21). Different types of chains can confer increased risk (chains of risk) or advantage (protective chains). Model 3 denotes a chain of risk that leads to the development of researchable hypotheses. The sequential links in model 3 are probabilistic rather than deterministic. There are multiple pathways in model 3 whereby exposures may increase health risk/advantage. Understanding chains of risk or accumulation of risk is dependent on how labor market and social contexts cluster exposures into specific sequences. For example, model 3 could be stratified (as in model 2) demonstrating health risk is higher for workers in lower statuses or more unequal societies (10).

Trajectories refer to a long-term view of a particular dimension (eg, a physiological, psychological or social state) of an individual life over time $(35,36)$. Labor markets and health trajectories are centered around "work", one social state identified by Kuh and colleagues (21). Labor markets and health trajectories incorporate labor market experiences, labor market transitions, life course transitions, health state transitions, health states, and health outcomes to create and describe a working life course. They take into account that health and work are interdependent and that work and non-work states and transitions are interrelated. Finally, labor markets and health trajectories are embedded in (or take place within) labor markets and social contexts that shape these trajectories.

As many as four contextual levels can influence a persons' working life course at a point in time (see table 2). The policies and interventions that social actors implement in a particular labor market and social context can change over time. Consequently, their effect on the working life course may be different across time periods. To more accurately capture the complex interplay of contexts and working life courses over time requires considering labor markets and health trajectories. An illustrative labor markets and health trajectory, model 4 that builds on model 3 , shows how, from the entry point into the labor market, the context ultimately 
shapes the trajectory in regards to both future labor market experiences and health states. For example, in model 4, the first labor market experience (unemployed looking for work) is dependent upon the broader labor market context where limited opportunities to participate in job training programs exist (37). Therefore, limited job training opportunities coupled with the lack of a high school diploma make it challenging for the person to find a job. In contrast, a model with a supportive context, (ie, access to effective job training programs) may lead to a successful transition into the labor market. Three of the four labor market and social context levels described in table 2 are presented in model 4 . Though not shown in model 4 , the contextual levels can operate at the same time. Model 4 can be readily extended to consider the effect of the working life course on health at older ages and/or multiple retirement and work transitions and their influence on health.

\section{Illustration of the life course perspective integrated into the labor markets and health framework}

An illustration drawn from unemployment health research shows how the integration of the life course perspective into the labor markets and health framework fundamentally changes the focus of the research questions and of where to effectively intervene across the life course. The application of the labor markets and health framework with a life course perspective places less emphasis on unemployment as an individual risk factor, and reframes unemployment as an experience in which its effect on health is fundamentally shaped by place and time. In the effect of unemployment on health and the health effect on unemployment, it is the "where", the "when" and the "to whom" that matters (38). The causal effect of unemployment on health emerges from considering its contextual and life course characteristics. Under what circumstances does unemployment take place during a sensitive period or represent a transition? And how does unemployment shape the accumulation of health risk and working life trajectories? The illustrative working life course described earlier highlights unemployment early in the workers' career as taking place during a sensitive period and being a transition - the transition from education to work. These first episodes of unemployment were, in part, due to poor mental health and low educational attainment. It is the combination of these three factors that influence the subsequent working life trajectory, leading to future unemployment, work disability and ultimately early retirement. The causal chain leading from health to unemployment to health is complex and requires a clear articulation of the sequencing, pathways and mechanisms across the life course in deriving research hypothesis and methods that lead to causal inference. Understanding this causal chain points to where and how intervention needs to be targeted in reducing the negative health effects of unemployment.

The application of the labor markets and health framework with a life course perspective (i) places priority on intervention earlier in the life course that would reduce the likelihood of unemployment and (ii) emphasizes that, once unemployment occurs, an effective intervention is one that reduces the "critical" nature of the unemployment transition by minimizing the effect the unemployment episode has on subsequent labor market and health trajectories (39).

\section{Implications for research and conclusion}

Table 4 presents research questions that integrate life course concepts into work and health research.

Emphasizing the temporal and contextual dependency of labor market experiences and labor market transitions guides research questions towards sensitive periods, which may differ across trajectories. Because sensitive periods are when and where policies and interventions across the working life course may be most effective in creating successful labor markets and health trajectories, the identification of sensitive periods is a key research priority. Future research needs to examine

Table 4. Research questions: labor markets and health trajectories

Transition(s)

- What are important transitions?

- Are some transitions more important than others?

- What are the characteristics of a successful transition?

- How do transitions shape trajectories?

- How do transitions in specific social contexts create health risk/ advantage?

Critical period(s)

- What is the etiologic relevant period?

- What are the effects of adverse/protective early life exposures on future (working) life outcomes?

Sensitive period(s)

- What is the etiologic relevant period?

- How do sensitive periods affect future labor market experiences, transitions or health?

Accumulation of health risk / advantage

- How do factors / exposures accumulate over the working life course?

- How do (different) factors / exposures cluster over time?

Trajectories in the social context

- How does the social context shape labor market and health trajectories?

- What are the characteristics of labor market and health trajectories that lead to positive health outcomes over the life course? 
what creates cumulative advantage (or risk) over the working life course by using data collected at multiple time points, linked within individuals and across contextual levels over time. The focus on understanding the various contextual levels and the constituent influence of social actors on labor markets and health trajectories will help identify policy and interventions that can both reduce health risk and build health advantage. For example, one important research question is to identify what are the contextual policies and interventions that will ameliorate the potential adverse health consequences of youth unemployment in later life.

Furthermore, it may be relevant to (i) consider a set of labor markets and health trajectories that hypothetically build health advantage; (ii) focus on the later life adverse health consequences of earlier critical periods and/or sensitive periods such as youth unemployment and work disability; (iii) focus on demographic, sociopolitical and labor market challenges different (vulnerable) groups face across the life course, eg, young workers, not successfully employed, workers with chronic health conditions or middle-aged and older workers; and (iv) understand the role of various contextual levels in shaping labor markets and health trajectories to identify relevant policies and interventions. Research on these priorities will inform policies and interventions that will help maintain a healthy and productive workforce and enable active ageing at work and beyond.

\section{Acknowledgements}

Chris McLeod is supported, in part, by a Canadian Institutes of Health Research New Investigator Award. His participation was supported through a Peter Wall Institute for Advanced Studies Early Career Scholar Award. Ute Bültmann and Ben Amick received no funding to complete this paper. All three authors, BA, $\mathrm{CMcL}$ and $\mathrm{UB}$, were involved in the conceptualization, drafting and editing of the paper. The authors report no conflicts of interest.

\section{References}

1. Clougherty JE, Souza K, Cullen MR. Work and its role in shaping the social gradient in health. Ann N Y Acad Sci. 2010 Feb;1186(1):102-24. http://dx.doi.org/10.1111/j.17496632.2009.05338.x.

2. Black C. Working for a healthier tomorrow. Dame Carol Black's review of the health of Britian's working age population. London, UK; 2008.

3. Berkman LF, Kawachi I, Theorell T. Working Conditions and Health. In: Berkman LF, Kawachi I, Glymour MM, editors. Social Epidemiology. 2nd ed. New York, NY: Oxford Univerisity Press; 2014. p. 153-81. http://dx.doi.org/10.1093/ $\mathrm{med} / 9780195377903.003 .0005$.

4. Sabbath EL, Guevara IM, Glymour MM, Berkman LF. Use of Life Course Work-Family Profiles to Predict Mortality Risk Among US Women. Am J Public Health. 2015 Apr;105(4):e96-102. http://dx.doi.org/10.2105/ AJPH.2014.302471.

5. Sabbath EL, Mejía-Guevara I, Noelke C, Berkman LF. The long-term mortality impact of combined job strain and family circumstances: A life course analysis of working American mothers. Soc Sci Med. 2015;146:111-9. http://dx.doi. org/10.1016/j.socscimed.2015.10.024.

6. Krieger N. Epidemiology and the People's Health Theory and Context. New York, NY: Oxford University Press; 2011. http:// dx.doi.org/10.1093/acprof:oso/9780195383874.001.0001.

7. McLeod CB, Hall PA, Siddiqi A, Hertzman C. How society shapes the health gradient: work-related health inequalities in a comparative perspective. Annu Rev Public Health. 2012 Apr 21;33:59-73. http://dx.doi.org/10.1146/annurevpublhealth-031811-124603.

8. Bann D, Hardy R, Cooper R, Lashen H, Keevil B, Wu $\mathrm{FCW}$, et al. Socioeconomic conditions across life related to multiple measures of the endocrine system in older adults: Longitudinal findings from a British birth cohort study. Soc Sci Med. 2015;147:190-9. http://dx.doi.org/10.1016/j. socscimed.2015.11.001.

9. Lipscomb HJ, Loomis D, McDonald MA, Argue RA, Wing S. A conceptual model of work and health disparities in the United States. Int J Health Serv. 2006;36(1):25-50. http:// dx.doi.org/10.2190/BRED-NRJ7-3LV7-2QCG.

10. McLeod CB, Lavis JN, MacNab YC, Hertzman C. Unemployment and Mortality: A Comparative Study of Germany and the United States. Am J Public Health. 2012 Jun 14;102(8):1542-50. http://dx.doi.org/10.2105/ AJPH.2011.300475.

11. Benach J, Vives A, Amable M, Vanroelen C, Tarafa G, Muntaner C. Precarious Employment: Understanding an Emerging Social Determinant of Health. Annu Rev Public Health. Annual Reviews; 2014 Mar 18;35(1):229-53.

12. Veldman K, Reijneveld SA, Almansa Ortiz J, Verhulst FC, Bultmann U. Mental health trajectories from childhood to young adulthood affect the educational and employment status of young adults: results from the TRAILS study. J Epidemiol Community Health. 2015;69(6):588-93. http://dx.doi. org/10.1136/jech-2014-204421.

13. Amick BC, Mustard CA. Labor markets and health: A social epidemiological perspective. In: Bianchi SM, Casper LM, King RB, editors. Work, Family, Health and Well-Being. Mahwan, NJ: Lawrence Erlbaum; 2005. p. 409-28.

14. Amick BC, Lavis JN. Labor markets and health. A framework and set of applications. In: Tarlov AR, St.Peter RF, editors. The Society and Population Health Reader: A State and Community Perspective. New York: The New Press; 2000. p. 178-210. 
15. Bronfenbrenner U. The Ecology of Human Development: Experiments by Nature and Design. Cambridge, MA: Harvard University Press; 1979.

16. Sampson RJ, Laub JH. A life course theory of cumulative disadvantage and the stability of delinquency. In: Thornberry TP, editor. Developmental Theories of Crime and Delinquency: Advances in Criminological Theory. New Brunswick, NJ: Transaction; 1997. p. 133-61.

17. Mayer KU. New Directions in Life Course Research. Annu Rev Sociol. 2009 Aug;35(1):413-33. http://dx.doi. org/10.1146/annurev.soc.34.040507.134619.

18. Elder Jr. GH, Kirkpatrick Johnson M, Crosnoe R. The Emergence and Development of Life Course Theory. In: Mortimer JT, Shanahan MJ, editors. Handbook of the Life Course. New York, NY: Kluwer Academic/Plenum Publishers; 1997. p. 3-19.

19. Corna LM. A life course perspective on socioeconomic inequalities in health: A critical review of conceptual frameworks. Adv Life Course Res. 2013;18(2):150-9. http:// dx.doi.org/10.1016/j.alcr.2013.01.002.

20. Ben-Shlomo Y, Kuh D. A life course approach to chronic disease epidemiology: conceptual models, empirical challenges and interdisciplinary perspectives. Int J Epidemiol. 2002 Apr 1;31(2):285-93. http://dx.doi.org/10.1093/ije/31.2.285.

21. Kuh D, Ben-Shlomo Y, Lynch J, Hallqvist J, Power C. Life course epidemiology. J Epidemiol Community Health. 2003;57:778-83. http://dx.doi.org/10.1136/jech.57.10.778.

22. Halfon N, Hochstein M. Life course health development: An integrated framework for developing health, policy, and research. Milbank Q. 2002;80(3):433-79. http://dx.doi. org/10.1111/1468-0009.00019.

23. Pavalko EK, Caputo J. Social Inequality and Health Across the Life Course. Am Behav Sci. 2013 May 15;57(8):1040-56. http://dx.doi.org/10.1177/0002764213487344.

24. Zapf D, Dormann C, Frese M. Longitudinal studies in organizational stress research: a review of the literature with reference to methodological issues. J Occup Health Psychol. 1996 Apr;1(2):145-69. http://dx.doi.org/10.1037/1076-8998.1.2.145.

25. Burstyn I, Teschke K. Studying the Determinants of Exposure: A Review of Methods. Am Ind Hyg Assoc J. 1999 Jan 1;60(1):5772. http://dx.doi.org/10.1080/00028899908984423.

26. House JS. Understanding social factors and inequalities in health: 20th century progress and 21 st century prospects. J Health Soc Behav. 2002;43(2):125-42. http://dx.doi. org/10.2307/3090192.

27. Shim MJ, Gimeno D, Pruitt SL, McLeod CB, Foster MJ, Amick III BC. A systematic review of retirement as a risk factor for mortality. In: Hoque N, McGehee MA, Bradshaw BS, editors. Applied Demography and Public Health. Dordrecht: Springer Netherlands; 2013. p. 277-300. http:// dx.doi.org/10.1007/978-94-007-6140-7 17.

28. McMunn A, Bartley M, Hardy R, Kuh D. Life course social roles and women's health in mid-life: causation or selection?
J Epidemiol Community Health. 2006;60(6):484-9. http:// dx.doi.org/10.1136/jech.2005.042473.

29. Flint E, Bartley M, Shelton N, Sacker A. Do labour market status transitions predict changes in psychological well-being? J Epidemiol Community Health. 2013 Jun 28;67(9):796-802. http://dx.doi.org/10.1136/jech-2013-202425.

30. Leist AK, Hessel P, Avendano M. Do economic recessions during early and mid-adulthood influence cognitive function in older age? J Epidemiol Community Health. 2014 Feb; 68(2):151-8. http://dx.doi.org/10.1136/jech-2013-202843.

31. Stone J, Evandrou M, Falkingham J, Vlachantoni A. Women's economic activity trajectories over the life course: implications for the self-rated health of women aged 64+ in England. J Epidemiol Community Health. 2015 Sep;69(9):873-9. http:// dx.doi.org/10.1136/jech-2014-204777.

32. Norder G, Roelen CA, Bültmann U, van der Klink JJ. Shift work and mental health sickness absence: a 10 -year observational cohort study among male production workers. Scand J Work Environ Health. 2015;30(2):81-4. http://dx.doi. org/10.5271/sjweh.3501.

33. Frohlich KL, Potvin L. Transcending the Known in Public Health Practice: The Inequality Paradox: The Population Approach and Vulnerable Populations. Am J Public Health. 2008 Feb 1;98(2):216-21. http://dx.doi.org/10.2105/ AJPH.2007.114777.

34. Amick BC, McDonough P, Chang H, Rogers WH, Pieper CF, Duncan G. Relationship between all-cause mortality and cumulative working life course psychosocial and physical exposures in the United States labor market from 1968 to 1992. Psychosom Med. 2002;64(3):370-81. http://dx.doi. org/10.1097/00006842-200205000-00002.

35. Elder GH, Pavalko EK. Work Careers in Men's Later Years Transitions, Trajectories, and Historical Change. J Gerontol. 1993 Jul 1;48(4):S180-91. http://dx.doi.org/10.1093/ geronj/48.4.S180.

36. Pavalko EK, Smith B. The Rhythm of Work: Health Effects of Women's Work Dynamics. Soc Forces. 1999 Mar 1;77(3):1141-62. http://dx.doi.org/10.1093/sf/77.3.1141.

37. Gangl M. Welfare States and the Scar Effects of Unemployment: A Comparative Analysis of the United States and West Germany. Am J Sociol. 2004 May;109(6):1319-64. http:// dx.doi.org/10.1086/381902.

38. Reeves A, Karanikolos M, Mackenbach J, McKee M, Stuckler D. Do employment protection policies reduce the relative disadvantage in the labour market experienced by unhealthy people? A natural experiment created by the Great Recession in Europe. Soc Sci Med. E2014;121:98-108. http://dx.doi. org/10.1016/j.socscimed.2014.09.034.

39. McLeod CB. Unemployment in context and comparison: a study of Canada, Germany and the United States of America. University of British Columbia; 2009.

Received for publication: 16 September 2015 